ACCEPTED MANUSCRIPT

\title{
Sol-gel TiO2 colloidal suspensions and nanostructured thin films: structural and biological assessments
}

To cite this article before publication: Elsa Quartapelle Procopio et al 2017 Nanotechnology in press https://doi.org/10.1088/1361-6528/aa9ca0

\section{Manuscript version: Accepted Manuscript}

Accepted Manuscript is "the version of the article accepted for publication including all changes made as a result of the peer review process, and which may also include the addition to the article by IOP Publishing of a header, an article ID, a cover sheet and/or an 'Accepted Manuscript' watermark, but excluding any other editing, typesetting or other changes made by IOP Publishing and/or its licensors"

This Accepted Manuscript is @ 2017 IOP Publishing Ltd.

During the embargo period (the 12 month period from the publication of the Version of Record of this article), the Accepted Manuscript is fully protected by copyright and cannot be reused or reposted elsewhere.

As the Version of Record of this article is going to be / has been published on a subscription basis, this Accepted Manuscript is available for reuse under a CC BY-NC-ND 3.0 licence after the 12 month embargo period.

After the embargo period, everyone is permitted to use copy and redistribute this article for non-commercial purposes only, provided that they adhere to all the terms of the licence https://creativecommons.org/licences/by-nc-nd/3.0

Although reasonable endeavours have been taken to obtain all necessary permissions from third parties to include their copyrighted content within this article, their full citation and copyright line may not be present in this Accepted Manuscript version. Before using any content from this article, please refer to the Version of Record on IOPscience once published for full citation and copyright details, as permissions will likely be required. All third party content is fully copyright protected, unless specifically stated otherwise in the figure caption in the Version of Record.

View the article online for updates and enhancements. 


\title{
Sol-gel $\mathrm{TiO}_{2}$ colloidal suspensions and nanostructured thin films:
}

\section{structural and biological assessments}

Elsa Quartapelle Procopio, ${ }^{\text {a }}$ Valentina Colombo, ${ }^{a}$ Nadia Santo, ${ }^{b}$ Angelo Sironi, ${ }^{\text {a,d }}$ Cristina Lenardi, ${ }^{\mathrm{c}, \mathrm{d}}$ Daniela Maggioni ${ }^{\mathrm{a}, \mathrm{d}^{*}}$

${ }^{a}$ Dipartimento di Chimica, Università degli Studi di Milano,Via Golgi 19, 20133 Milano, Italy. ${ }^{b}$ Dipartimento di Bioscienze, Università degli Studi di Milano, Via Celoria 22, 20133 Milano, Italy.

${ }^{c}$ CIMAINA, Dipartimento di Fisica, Università degli Studi di Milano, Via Celoria 16, 20133 Milano, Italy.

${ }^{d}$ Consorzio INSTM, via G. Giusti 9, 50121, Firenze, Italy.

E-mail: daniela.maggioni@unimi.it

\begin{abstract}
The role of the substrate topography in phenotypes expression of in-vitro cultured cells has been widely assessed. However, the production of nanostructured interface via deposition of solgel synthetized nanoparticles has not yet fully exploited. This is also argued by the limited number of studies correlating the morphological, structural and chemical properties of the grown thin films with those of the sol-gel "brick" within the framework of the bottom-up approach. Our work intends to contribute to go beyond this drawback presenting an accurate investigation of sol-gel $\mathrm{TiO}_{2}$ nanoparticles shaped as spheres and rods. They have been fully characterized by complementary analytical techniques both suspended in apolar solvents, by dynamic light
\end{abstract}


scattering (DLS) and nuclear magnetic resonance (NMR) and after deposition on substrates (solid state configuration) by transmission electron microscopy (TEM) and powder x-ray diffraction (PXRD). In the case of suspended anisotropic rods, the experimental DLS data, analyzed by Tirado-Garcia de la Torre model, present the following ranges of dimensions: 4-5 $\mathrm{nm}$ diameter $(\varnothing)$ and 11-15 nm length (L). These results are in good agreement with what obtained by the two solid state techniques, namely 3.8(9) nm $\varnothing$ and 13.8(2.5) nm L from TEM and 5.6(1) $\varnothing$ and 13.3(1) nm L from PXRD data.

To prove the suitability of the supported sol-gel NPs for biological issues, spheres and rods have been separately deposited on cover-slips. The cell response has been ascertained by evaluating the adhesion of the epithelial cell line Madin-Darby Canine Kidney. The cellular analysis showed that titania films promote cell adheșion as well the clustering organization, which is a distinguishing feature of this type of cell line. Thus the use of nanostructured substrates via sol-gel could be considered a good candidate for cell culture with the further advantages of likely scalability and interfaceability with many different materials usable as supports.

Keywords: titanium dioxide, nanoparticles, sol-gel, thin film, MDCK cells

\section{Introduction}

Nowadays biomimetic research is widespread and this indicates that many natural phenomena are related to the micro and nano-structures present on the biosurfaces [1,2]. In the last years many works focused on the role of substrate topography in cellular proliferation and differentiation, as well as on the possibility to manufacture biocompatible interfaces able to mimic the physiological conditions of the extracellular environment [2]. Moreover, the cellular 
behaviour, both in vivo and in vitro, is influenced by mechanical, biochemical and topographic properties of the extracellular microenvironment [3].

In particular, the biochemical composition and the mechanical behavior of the extracellular matrix play an important role in many processes like morphogenesis [4], differentiation [5], development of tumors [6,7], etc. Cells can actively adapt to the adhesion surface and activate specific intracellular signals, which affect their behavior and survival $[8,9]$. In vivo, cellular adhesion is the consequence of the binding to extracellular matrix through cellular specificadhesion proteins. The protein binding is intrinsically affected by mechanical and chemical signals deriving from topography of external environment which is characterized by objects of different size scale, from the nano to the mesoscale $[10,11]$. On the other hand, in vitro cells establish a complex network of interactions both with the artificial surface and the secreted proteins as well as with the serum proteins of extracellular matrix. The optimization of the cellsubstrate interactions can consequently open new perspectives in the design of biomimetic supports $[12,13]$.

In this work we focused our attention on titanium dioxide as substrate material for cell culture studies. $\mathrm{TiO}_{2}$ nanoparticles are a very valuable functional material, with properties strongly depending on the crystalline phase (anatase, rutile or brookite) afforded by the synthetic procedures. Nanocrystalline $\mathrm{TiO}_{2}$ is used in photocatalysis [14-17], dye-sensitized solar cells and electronic devices $[18,19]$. Among many materials, titania has also been studied in several works on cellular proliferation due to its peculiar properties. Many efforts have been devoted on the study of the topographic modifications of titania surfaces, since $\mathrm{TiO}_{2}$ is among the most studied biomaterials [20]. It has already been shown how stem cells answer differently to different extracellular matrixes with relevant consequences on their differentiation and selfrenewal $[21,22]$. More recently it has been reported that, independently from the employed cell types, a nanostructured topography constituted by anatase phase $\mathrm{TiO}_{2}$ nanotubes (produced by anodization of Ti sheets in a phosphate-fluoride electrolyte) with a 15-20 nm diameter induces 
stronger stimulation on differentiation, cell adhesion, proliferation, and motility, than amorphous $\mathrm{TiO}_{2}$ and/or nanotubes with greater diameters [23].

Often, top-down methods are used to obtain micro and nanostructured substrates, like the hard or the soft lithography [24], nevertheless these techniques are not usually able to produce substrates with morphology and hierarchical organization like in extracellular matrix is [25].

In the literature there exist several examples of studies on cell interaction with nanostructured materials obtained with a bottom-up approach [26], but among them only a few are based on solgel nanoparticles deposition [27]. For this reason, in this work we have prepared, characterized and tested two different types of substrate, obtained by a wet-chemical method, by using spheres or rods as precursor bricks deposited on coverslips.

The assessment of a nano-object size and shape has been achieved by solid state techniques; however, the results provided by deposited samples could be biased by aggregation processes, resulting in size and/or shape modifications. On the other hand, while many applications require NPs in the liquid state or as a heterogeneous stable suspension, solution approaches are not always informative as far as NPs' shape is concerned. Therefore, the use of a single technique either in the solid state or in solution cannot be completely satisfactory for the determination of size and shape of nanoparticles.

Concerning the sol-gel method, we prepared both $\mathrm{TiO}_{2}$ nanospheres and nanorods [28], and studied them through the complementary role of solution (DLS and NMR) and solid state (TEM and PXRD) analytical techniques. These sol-gel materials have been then employed to produce drop casted thin films of nanostructured $\mathrm{TiO}_{2}$ supported on round glass coverslips as substrates for epithelial cells (MDCK, Madin-Darby Canine Kidney) adhesion and proliferation studies. For comparison the same set of biological experiments have been performed on nanostructured $\mathrm{TiO}_{2}$ thin films produced by supersonic beam deposition of clusters, whose use as titania substrates for cell growth has been widely assessed [29,30]. 


\section{Experimental section}

\subsection{Sample preparation}

2.1.1. Synthesis of spherical $\mathrm{TiO}_{2} @ O A$ nanoparticles. The synthesis of spherical and rod-like $\mathrm{TiO}_{2} @ \mathrm{OA}$ was derived from a literature procedure [28]. Briefly, triethylamine (TEA) and ethylenglycole (EG) were treated with $4 \AA$ molecular sieves for $24 \mathrm{~h}$ and then distilled (the first one from $\mathrm{P}_{2} \mathrm{O}_{5}$, the second one in reduced pressure). Technical oleic acid (OA, 90\%) was dried under vacuum heating at $120^{\circ} \mathrm{C}$ for at least $1 \mathrm{~h}$ under vigorous stirring. Typically, $40 \mathrm{~mL}$ of dried OA were warmed at $100{ }^{\circ} \mathrm{C}$ and added with $4.5 \mathrm{~mL}$ of titanium tetraisopropoxide (TTIP, $1.5 \mathrm{mmol})$, then a solution of TEA $(0.42 \mathrm{~mL}, 3 \mathrm{mmol})$ in anhydrous EG $(2.2 \mathrm{~mL})$ was added and the sol-gel reaction left to proceed for more than $60 \mathrm{~h}$ at $100^{\circ} \mathrm{C}$. The solution remained clear and no precipitate was observed. Part of the solution $(2 \mathrm{~mL})$ was then treated with $6 \mathrm{~mL}$ of ethanol or methanol under stirring and immediately a white precipitate formed. The suspension was centrifuged for $10 \mathrm{~min}$ at $3500 \mathrm{rpm}$, discarded the supernatant, re-dissolved in $2 \mathrm{~mL}$ of $\mathrm{CHCl}_{3}$ and repeated the precipitation until a white and powdery precipitate was obtained.

2.1.2. Synthesis of rod-like $\mathrm{TiO}_{2} @ O A$ nanoparticles. Anhydrous OA was warmed at $100{ }^{\circ} \mathrm{C}$, added with $2.25 \mathrm{~mL}$ of TTIP $(0.75 \mathrm{mmol})$ under stirring. Then $3.75 \mathrm{~mL}$ of an aqueous solution 2 M of tetraethylammonium hydroxide was rapidly added. The solution was left under stirring and mild reflux at $100{ }^{\circ} \mathrm{C}$ for $6 \mathrm{~h}$. The solution became turbid, also after removing the water excess under vacuum. Similarly, to what done in the case of the spherical $\mathrm{TiO}_{2} @ \mathrm{OA}$ nanoparticles synthesis, the nanorod particles were recovered by treating $2 \mathrm{~mL}$ of suspension with $8 \mathrm{~mL}$ of ethanol or methanol, centrifuged at $3600 \mathrm{rpm}$ for $20 \mathrm{~min}$, repeating the procedure twice in order to remove the OA excess. Both spheres and rods were completely soluble in $\mathrm{CHCl}_{3}$, giving colorless and stable suspensions.

2.1.3. Sol gel-based thin films preparation. Round glass coverslips with a diameter of $13 \mathrm{~nm}$ were sonicated (Branson 5510 working at $42 \mathrm{kHz}$ ) in different solvents by following subsequent washing cycles which employed acetone, ethanol, milliQ water and isopropanol, $10 \mathrm{~min}$ for each 
solvent. Afterward, the coverslips have been dried by using a gentle nitrogen flux. Then, in a typical preparation, $10 \mathrm{mg}$ of $\mathrm{TiO}_{2}$ nanospheres or nanorods were suspended in $5 \mathrm{~mL}$ of $\mathrm{CHCl}_{3}$, and $1 \mathrm{~mL}$ was further diluted adding $24 \mathrm{~mL}$ of $\mathrm{CHCl}_{3}$. The diluted suspension was sonicated for 15 min, immediately after, by using a $0.2 \mu \mathrm{m}$ PTFE (polytetrafluoroethylene) syringe frit, $30 \mu \mathrm{L}$ were drop-casted on a glass coverslip completely and uniformly covering the entire surface. The solvent was then made slowly evaporate. Finally, the covered glass coverslips were calcined at $450{ }^{\circ} \mathrm{C}$ reaching the final temperature at a rate of $10.6{ }^{\circ} \mathrm{C} / \mathrm{min}$, leaving the coverslip for $2 \mathrm{~h}$ at $450{ }^{\circ} \mathrm{C}$, then pulling them out of the oven to let them slowly cool down to room temperature.

2.1.4. Cluster-assembled nanostructured substrates. Nanostructured ns-TiOx films were produced by supersonic cluster beam deposition (SCBD) using an apparatus equipped with a pulsed microplasma cluster source (PMCS) [31]. The PMCS operation principle is based on the ablation of a target titanium rod by pulsed argon plasma ignited by an electric discharge. The ablated titanium atoms thermalize in the quenching gas and aggregate to form clusters. The mixture of clusters and inert gas is then extracted into an expansion chamber through an aerodynamic filter and forms a seeded supersonic beam.

A glass coverslip placed on a manipulator intersects perpendicularly the beam trajectory allowing the deposition of the clusters (rate of about $0.5-2.5 \mathrm{~nm} / \mathrm{min}$ ). The nanostructured film is grown under ballistic deposition regime. The clusters partially oxidize in the source and in the deposition chamber due to the presence of oxygen in trace. The oxidation further proceeds upon exposure to air resulting in a ns-TiOx $(\mathrm{x} \leq 2)$ film, as assessed via electron spectroscopy [32]. The roughness was determined by means atomic force microscopy (AFM) and, for the used deposition parameters, results to be $20 \pm 0.5 \mathrm{~nm}$ [30].

\subsection{Characterization experiments}

2.2.1 NMR. ${ }^{1} \mathrm{H}$ Pulsed field Gradient Spin Echo (PGSE) NMR experiments were on a Bruker 400DRX spectrometer equipped with a $\mathrm{BBI}$ probe and z-gradients, at $300 \mathrm{~K}$ in $\mathrm{CHCl}_{3} / \mathrm{CDCl}_{3}$ (9/1) or in $\mathrm{CDCl}_{3}$, on diluted samples (typically NMR samples were prepared dissolving 3 mg of 
surfacted $\mathrm{TiO}_{2}$ nanoparticles in $500 \mu \mathrm{L}$ of protio or deuterated solvent). A $3 \mathrm{~mm}$ ID capillary tube was always used in order to minimize convective motions.

Chloroform was chosen as solvent since it has the advantage to well dissolve the nanoparticles giving clear solutions and also because, among the apolar deuterated solvents available, it had the right properties, as relaxation time not too long (as benzene and toluene) in order to be used as internal standard too, one single resonance not overlapping with oleate resonances (as hexane, cyclehexane and so on). Finally, $\mathrm{CD}_{2} \mathrm{Cl}_{2}$ was discarded because of the presence of severer convective motions. The gradient strength $(G)$ was linearly incremented in 16 steps, from $5 \%$ to $95 \%$ of its maximum value $\left(G_{\max }=53.5 \mathrm{G} / \mathrm{cm}\right)$. The gradient pulses used were sine shaped. Diffusion time $(\Delta)=200-600 \mathrm{~ms}$ and gradient pulse duration $(\delta)=2.4 \mathrm{~ms}$ were normally used. The gradient strength was varied from $30 \%$ to $95 \%$ in order to have a minor contribution of OA free in the case of a ligand excess, and recovery delay was left longer than 12 s. Standard deviations of the diffusion coefficients were obtained from the linear fitting of equation S2 (where $\gamma$ is the gyromagnetic ratio of ${ }^{1} \mathrm{H}$ and $\tau$ represents the time between bipolar gradients) [33], and the standard deviations of the hydrodynamic radii were computed accordingly, using Origin data analysis software package.

2.2.2. DLS. The Dynamic Light Scattering analysis of diluted samples (ca $1 \mathrm{mg} / \mathrm{mL}$ or less) were recorded on Malvern Zetasizer Nano instrument, equipped with a $633 \mathrm{~nm}$ He/Ne laser, with the detector at an angle of $173.0^{\circ}$. The experiments were performed at a controlled temperature of $25^{\circ} \mathrm{C}$. The viscosity, the refractive index and dielectric constant of $\mathrm{CHCl}_{3}$ were taken as 0.542 mPa s, 1.446 and 4.81, respectively, and the refractive index and absorbance index of $\mathrm{TiO}_{2}$ were taken as 2.49 and 0.01 , respectively. All the measurements were performed scanning 10 times per experiment and repeating the measurement 5 times.

2.2.3. TEM. The samples suspended in $\mathrm{CHCl}_{3}$ (ca $0.4 \mathrm{mg} / \mathrm{mL}$ ) were deposited by drop casting onto a 300 mesh Formvar/Carbon coated copper grid, and left to go naturally to dryness for one night. The transmission electron microscopy images were obtained on the Energy Filtering TEM 
LEO 912AB (Zeiss) operating at $120 \mathrm{kV}$ and acquired using a CCD-BM/1K and the ESI vision software AnalySIS (Soft Imaging Systems, Muenster, Germany). The statistics has been obtained using the free software Image-J $1.37 \mathrm{v}$.

2.2.4. PXRD. Gently ground powders of the samples were deposited in the, $2 \mathrm{~mm}$ deep, hollow of an aluminum sample holder. Diffraction experiments were performed using $\mathrm{Cu}-\mathrm{K}_{\alpha}$ radiation $(\lambda=1.5418 \AA)$ on a vertical-scan Bruker AXS D8 Advance diffractometer in $\theta: \theta$ mode, equipped with a Goebel Mirror and a linear Position Sensitive Detector (PSD), with the following optics: primary and secondary Soller slits, $2.3^{\circ}$ and $2.5^{\circ}$, respectively; divergence slit, $0.1^{\circ}$; receiving slit, $2.82^{\circ}$. Generator setting: $40 \mathrm{kV}, 40 \mathrm{~mA}$. The nominal resolution for the present set-up is $0.08^{\circ} 2 \theta$ (FWHM of the $\alpha_{1}$ component) for the $\mathrm{LaB}_{6}$ peak at about $21.3^{\circ}(2 \theta)$.

Rietveld refinement profile fitting have been done, with the use of the software TOPAS-R, [34], on the two samples, assuming the anatase structure. For the nanosphere sample, the best fitting has been obtained through the description of the peak broadening with the TOPAS CS_L function [34]. However, this approach cannot be applied for anisotropic peak broadening that has been described, for the nanorod sample, through the usage of $4^{\text {th }}$ order spherical harmonics.

It should be noted that, in the collected powder patterns (see supporting information Figure S2), some peaks related to the aluminum of the sample holder can be observed. However, the regions of the patterns that include these peaks have been excluded from the Rietveld refinement, thus not affecting the goodness of the fitting. The refinements converged to $R_{w p}=4.27$ and $R_{\text {Bragg }}$ $=2.94$ for the nanospheres and to $\mathrm{R}_{\mathrm{wp}}=3.73$ and $\mathrm{R}_{\mathrm{Bragg}}=1.89$ for the nanorods.

The Scherrer CS of both samples were determined on 004 and 020 reflections from their fwhm values either measured on the experimental profile (by using the DIFFRAC.EVA software [35], vide infra) or calculated from the fitted profile, converging to 13.3(1) and 5.6(1) nm for 004 and 020, respectively. For the nanosphere sample, the CS_L crystallite size was refined to $14.0(1) \mathrm{nm}$. 
2.2.5. FTIR. Infrared spectra were acquired on a Bruker Vector22 instrument. Samples were dispersed in $\mathrm{KBr}$ and pressed in a pellet, recording the spectra between 4000 and $400 \mathrm{~cm}^{-1}$.

2.2.6. Contact angle measurements. The film static contact angles were measured by the sessile drop method [36]. The measurements were performed using an FTA100 (First Ten Ångstroms Inc.) instrument. The drop of $0.5-1 \mathrm{~mm}$ diameter was released from a tip of syringe on the sample surface at $20 \pm 1{ }^{\circ} \mathrm{C}$. Each measurement was recorded in 150 images taken within $5 \mathrm{~s}$ with a Pelco Model PCHM 575-4 camera (standard deviation $\sim 2^{\circ}$ ). The image analysis was performed by the FTA Windows Mode 4 software.

\subsection{Cell culture and cell adhesion assays.}

Immortalized Madin-Darby Canine Kidney epithelial cell line (MDCK) were cultured in Dulbecco's Modified Eagle's Medium (DMEM), supplemented with 10\% Fetal Bovine Serum (FBS), 2 mM L-Glutamine, $0.1 \mathrm{mM}$ non-essential amminoacid, $1.5 \mathrm{~g} / \mathrm{L}$ sodium bicarbonate, 1 mM sodium pyruvate, 100 units $/ \mathrm{mL}$ penicillin and $100 \mu \mathrm{g} / \mathrm{mL}$ streptomycin. Cells were grown in tissue culture flasks at $37{ }^{\circ} \mathrm{C}$ in controlled atmosphere $\left(5 \% \mathrm{CO}_{2}\right)$ until they reached the $70 \%$ confluence, then by using a solution of tripsine/EDTA (Sigma) they were seeded in the multiwell plates. For cell adhesion and proliferation MDCK cells were seeded at a concentration of $10^{4}$ cells per well to $13 \mathrm{~mm}$ diameter round glass coverslips drop-casted with sol-gel $\mathrm{TiO}_{2}$ nanospheres or $\mathrm{TiO}_{2}$ nanorods, covered with ns- $\mathrm{TiO}_{\mathrm{x}}$, not functionalized glass, and to TCPS (tissue culture plate surfaces, multiwell 24, TPP- Zellkultur und Labortechnologie, Switzerland). MDCK adhesion was studied by comparing the behavior of cells on the different substrates over time. Cells were observed each hour for the first four hours after cell plating, by taking four random fields pictures for each well with a Power Shot G6 Canon digital camera mounted on a Zeiss Axiovert 40 CFL inverted optical microscope using 10x objective lens. Each thin film layer was monitored in triplicate. Cells were also monitored each $24 \mathrm{~h}$ after the first $4 \mathrm{~h}$, until confluence was achieved by cells. Cells were counted as adhesive cells whenever the typical polygonal-like shape was observed, while round and pearl-color cells were counted as detached 
cells. Percentage of adhesion was then calculated as the ratio between the adherent cells and the total cell number for each picture ( $4 \mathrm{x}$ well; at least 3 wells per tested material), then the arithmetic media was finally calculated.

\section{Results and Discussion}

\subsection{Study of the size of spheres and rods-like $\mathrm{TiO}_{2} @ O A$ NPs in the colloidal and in the} solid phase forms synthesized with a wet bottom-up method.

$\mathrm{TiO}_{2}$ NPs have been prepared according to a sol-gel method [28], which produces at first $\mathrm{TiO}_{2}$ NPs capped with oleic acid as a surfactant $\left(\mathrm{TiO}_{2} @ \mathrm{OA}\right)$ that makes spheres and rods soluble in $\mathrm{CHCl}_{3}$, giving colorless and stable suspensions. The interest toward this particular synthesis is due to several factors: a) the synthesis is conducted at relatively low temperatures compared to hydrothermal methodologies (vide infra); b) NPs are formed in the anatase phase; c) NPs can be obtained in two different forms: nanorods or nanospheres, in dependence of the tunable reaction conditions. The possibility to test the same material with a different shape and verify how it can influence the cellular behaviour has been taken into account.

The ${ }^{1} \mathrm{H}$ NMR spectra of free oleic acid and of $\mathrm{TiO}_{2} @ \mathrm{OA}$ nanospheres and nanorods are reported in Figure 1.

Upon binding to NPs, the ${ }^{1} \mathrm{H}$ NMR OA signals are broadened due to the shortening of $\mathrm{T}_{2}$ in dependence to the increase of the correlation time, experienced by OA molecules when interacting with the NPs, the chemical shifts remaining unchanged. This broadening is more pronounced for the protons closer to the nanoparticle surface (see the barely observable $\mathrm{CH}_{2}$ in position 2 and 3 ), in line with the view that as the distance from the surface increases local segmental mobility increases as well. 


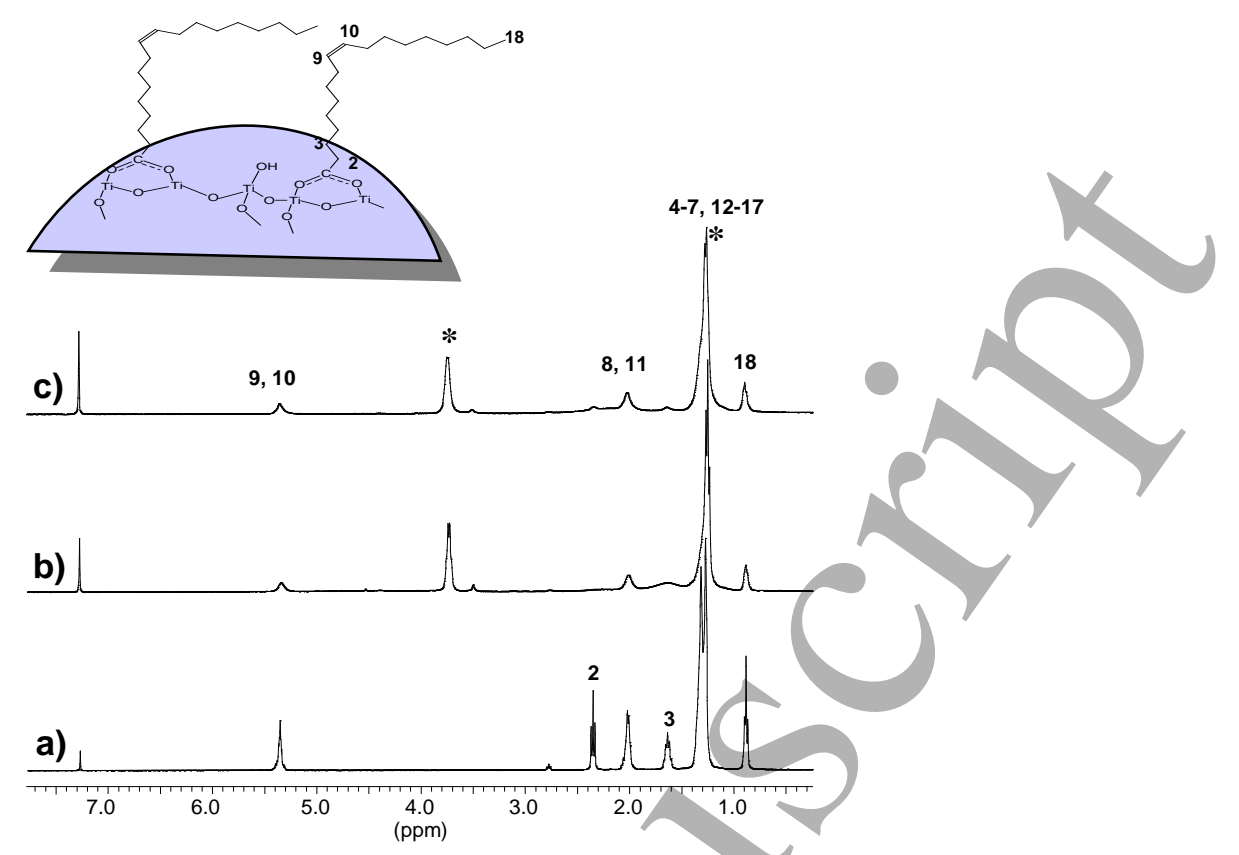

Figure 1. ${ }^{1} \mathrm{H}$ NMR spectra $\left(298 \mathrm{~K}, \mathrm{CDCl}_{3}\right)$ of (a) oleic acid; (b) $\mathrm{TiO}_{2} @ \mathrm{OA}$ nanospheres and (c) $\mathrm{TiO}_{2} @ \mathrm{OA}$ nanorods (asterisk marks $\mathrm{CH}_{2}$ and $\mathrm{CH}_{3}$ of ethanol).

The shorter $\mathrm{T}_{2}$ can give rise to a significant loss of magnetization during the pulse sequences used for diffusion measurements; therefore, not all the resonances of the surfactant molecules can be equally useful in NMR diffusion experiments.

In order to minimize the effects of $\mathrm{T}_{2}$ shortening and of possible convective motions, a double stimulated echo (DSTE) NMR pulse sequence (supporting information Scheme S1) has been used. Indeed, in spite of its intrinsic poor sensitivity, (only a quarter of the signal is retained), in this sequence (see Ref. [37]) the observed echo attenuation is coupled with the spin-lattice relaxation $T_{1}$ rather than the spin-spin relaxation $T_{2}$, (allowing measurements with longer diffusion times, $\Delta$ ), and the double stimulated echo compensate the possible effects of convective motions. In any case, since it is essential to get fixed information about the nanoparticle shape for the analysis of the diffusion data both from NMR and DLS, a TEM analysis was preliminarily performed (Figure 2). Figure 2 shows the micrographs of spherical nanoparticles (a), and of nanorods (c), while the analyses of the distribution sizes (b, d) showed that the diameter of the spherical NPs was centered at $6.5(1.1) \mathrm{nm}$ and that the diameter and 
length of the nanorods were 3.8(9) nm and 13.8(2.5) nm, respectively.
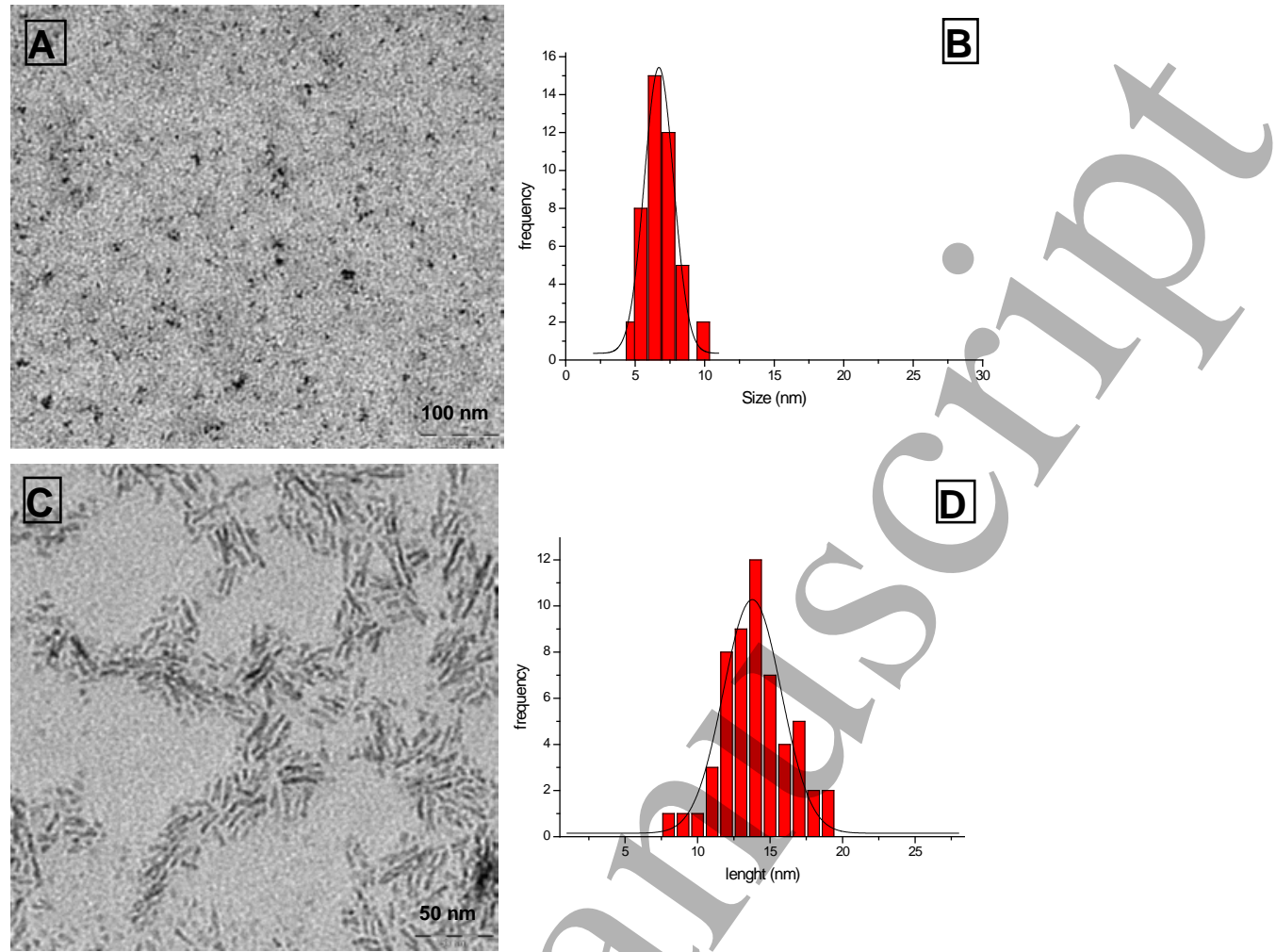

\section{D}

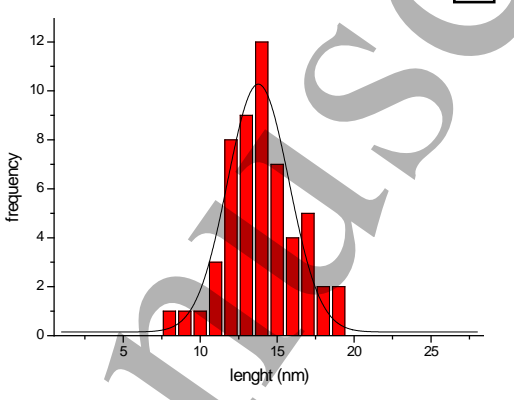

Figure 2. a) TEM image of a sample of $\mathrm{TiO}_{2}$ spheres, capped with oleic acid, deposited from a chloroform suspension; b) histogram distribution of the diameters; c) TEM image of a sample of $\mathrm{TiO}_{2}$ nanorods, capped with oleic acid, deposited from a chloroform suspension; d) histogram distribution of the rod length.

${ }^{1} \mathrm{H}$ DSTE NMR experiments were performed at $300 \mathrm{~K}$ in $\mathrm{CDCl}_{3}$ where $\mathrm{TiO}_{2} \mathrm{NPs}$ suspension appeared transparent and colorless. Figure 3 shows the gradient dependence, according to Equation S2, of the intensities of the $\mathrm{CH}_{3}$ signals of $\mathrm{OA}$ free and bound to $\mathrm{TiO}_{2} @ \mathrm{OA}$ nanospheres. Two different monoexponential slopes of the attenuation profiles were obtained, as expected due to the difference of size for the two entities, and therefore to the difference of diffusion coefficients $\mathrm{D}_{\mathrm{t}}$.

Three DSTE NMR experiments were performed on $\mathrm{TiO}_{2} @ \mathrm{OA}$ nanospheres using different $\Delta$ values. Only the slopes of the decays of the two most intense resonances $\mathrm{CH}_{2}$ (47, 12-17) at $1.28 \mathrm{ppm}$ and the one of $\mathrm{CH}_{3}$ (18) at $0.90 \mathrm{ppm}$ were used to estimate the diffusion coefficient, being the intensities of the other resonances too low for a meaningful 
analysis. The mean value of $D_{t}$ resulted $1.42 \cdot 10^{-10} \mathrm{~m}^{2} \mathrm{~s}^{-1}\left( \pm 6 \cdot 10^{-12}\right)$, which corresponds to a hydrodynamic diameter of $5.8(3) \mathrm{nm}$, value in agreement with the mean diameter of the inorganic core of nanospheres estimated by TEM analysis $(6.5(1.1) \mathrm{nm}$, see Figure 2 panel b).

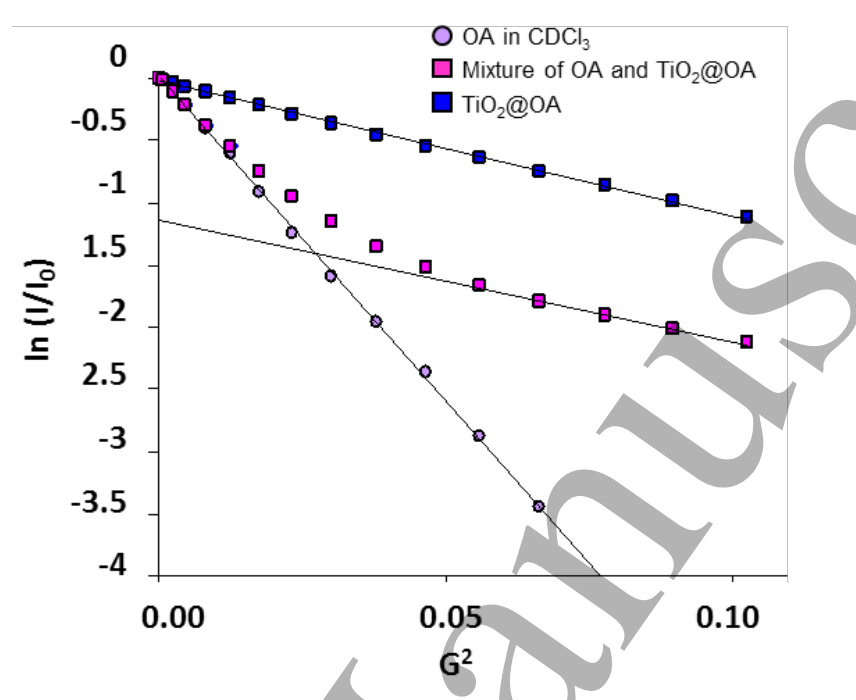

Figure 3. Comparison of the $\mathrm{CH}_{3}$ resonance echo attenuation for a sample of free $\mathrm{OA}, \mathrm{TiO}_{2} @ \mathrm{OA}$ nanospheres and of a mixture of $\mathrm{TiO}_{2} @ \mathrm{OA}$ nanoshperes and free $\mathrm{OA}\left(300 \mathrm{~K}, \mathrm{CDCl}_{3}, \Delta=200 \mathrm{~ms}\right.$, $\delta=2.4 \mathrm{~ms})$.

In principle, when dealing with polydispersed systems, the extent of polydispersion must be taken into account. Equation S2 can be modified in the empirical Kohlrausch-Williams-Watts (KWW) distribution function or stretched exponential [38,39], introducing a parameter $\beta$ (Equation 1) that describes the width of the distribution of the diffusion coefficients. $\beta$ values are in the range $0<\beta \leq 1$, the lower the $\beta$ value the higher the polydispersion.

$$
\ln \frac{I}{I_{0}}=-\left[(\gamma \delta)^{2} D_{t}\left(\Delta-\frac{\delta}{3}-\frac{\tau}{2}\right) G^{2}\right]^{\beta}
$$

Nevertheless, the fitting of the attenuation profiles through Equation 1 of both $\mathrm{TiO}_{2} @ \mathrm{OA}$ spheres and rods brought always to an estimation of the parameter $\beta \geq 0.95$, indicating a low polydispersion. ${ }^{1} \mathrm{H}$ PGSE NMR experiments are sensitive to the presence of surfactant excess. In Figure 3 it is also shown the attenuation profile of a sample of $\mathrm{TiO}_{2} @ \mathrm{OA}$ treated by the addition 
of an OA drop. While in the absence of an excess of free OA, the attenuation profile follows a mono-exponential decay, in the presence of free OA, the attenuation profile becomes biexponential, with a fast decay behaviour that overlaps the decay of the free OA at low gradient intensities, and a slow decay at high gradient intensities with the same slope as the $\mathrm{TiO}_{2} @ \mathrm{OA}$ sample.

NMR measurements can give insights on many aspects. According to computer simulations reported in the literature [40], the attenuation profile observed for the mixture of $\mathrm{TiO}_{2} @ \mathrm{OA}$ and OA (Figure 3) is in line with a two-site system $\left(\mathrm{OA}\right.$ free- $\left.\mathrm{TiO}_{2} @ \mathrm{OA}=\mathrm{A}-\mathrm{B}\right)$ in slow exchange regime on the NMR time scale, with a ratio of the diffusion coefficients of the two species of ca $10(\mathrm{DA}=10 \mathrm{DB})$ and with a relative population of the two sites $\mathrm{A}: \mathrm{B}=8: 2$.

DLS measurements have been performed in the presence of free OA. Despite the capability of resolution of NMR to measure in a bi-exponential decay the same diffusion coefficient for $\mathrm{TiO}_{2} @ \mathrm{OA}$ (see Figure 3) compared to the $\mathrm{D}_{\mathrm{t}}$ before the addition of the excess of OA free, DLS did not show the same resolution ability. In Figure S1 of supporting information it is reported the autocorrelation function decay for such a sample, whose fitting by a non-linear bi-exponential function (Equation 2) [41] led to the estimation of $D_{t}=5.5 \cdot 10^{-11} \mathrm{~m}^{2} \mathrm{~s}^{-1} \pm 2 \cdot 10^{-13}$, diameter 14.3 $\pm 1 \mathrm{~nm}$ (the second component $\mathrm{n}_{2}$ was necessary to take into account the presence of dust or some aggregate in the sample $5.3 \cdot 10^{-13} \mathrm{~m}^{2} \mathrm{~s}^{-1} \pm 4 \cdot 10^{-14}$, diameter $15 \mu \mathrm{m}, \mathrm{n}_{1} / \mathrm{n}_{2}=2.9 \cdot 10^{18}$ ).

$$
G(t)=0.15\left(\sum_{i} A_{i} e^{-D_{t} q t}\right)^{2}
$$

where $q$ the wave vector $=4 \pi \mathrm{n} /[\lambda \sin \theta / 2], \lambda$ the wavelength of the incident light $\left(\theta=90^{\circ}\right), \mathrm{n}=$ refractive index of $\mathrm{CHCl}_{3}(\mathrm{n}=1.4460), \mathrm{i}=2$, A is a pre-exponential factor that is proportional to the product of the square of the molecular mass times the number concentration, and with $D_{t}$ is estimated by the iterative fitting process [41]. 
Such an increase is likely due to the formation of many OA layers around the particles through apolar interactions between the linked and free aliphatic chains of OA in monomeric or dimeric forms.

PXRD patterns confirmed that in both samples (rods and spheres, [42] Figure S2 and S3) $\mathrm{TiO}_{2}$ is present as pure Anatase. However, an anisotropic broadening of the peaks, with sharper $00 l$ and broader $h 00$ (and $0 k 0$ ) reflections, is observed in the PXRD pattern of the nanorods thus revealing the anisotropic shape of its crystallites. Crystallite sizes where determined from the 004 and 020 reflections in this samples by applying the Scherrer equation (Eq. S3) on the fwhm values either measured on the experimental profile or calculated from the fitted profile. While for the nanosphere sample the crystal size is isotropic and equal to 14.0(1) nm (either for calculated and experimental fwhm), for the nanorod sample we have obtained crystal size values of 13.8(1) and 5.0(1) nm on the experimental profile and of 13.3(1) and 5.6(1) on the calculated one, obtained by Rietveld refinement.

As to $\mathrm{TiO}_{2}$ nanorods, measures of the translational diffusion coefficient by DLS and NMR led almost to the same diffusion coefficient $D_{t}$, which resulted equal to $8.4 \cdot 10^{-11} \mathrm{~m}^{2} \mathrm{~s}^{-1}\left( \pm 1 \cdot 10^{-12}\right)$ and $1.02 \cdot 10^{-10} \mathrm{~m}^{2} \mathrm{~s}^{-1}\left( \pm 1 \cdot 10^{-12}\right)$, respectively. Due to the anisotropy of these NPs, the values of $\mathrm{D}_{\mathrm{t}}$ cannot be used directly in the Stoke-Einstein equation (Eq. S1) for the obtainment of the size, but suitable models must be taken into account.

There exist many models relative to the correlation between the translational diffusion coefficient and dimension for rod-like nanoparticles: Tirado and Garcia de la Torre’s relations (TGT) [43,44] hydrodynamic stick theory (HST) [45] and the Broersma's relations (B) [46] while Perrin theory [47] is applied to rotational ellipsoids (so it has not been taken into account in this study). Table 1 reports the size ranges compatible with the experimental $D_{t}$ determined through NMR and DLS, according to the most accepted models cited above. 


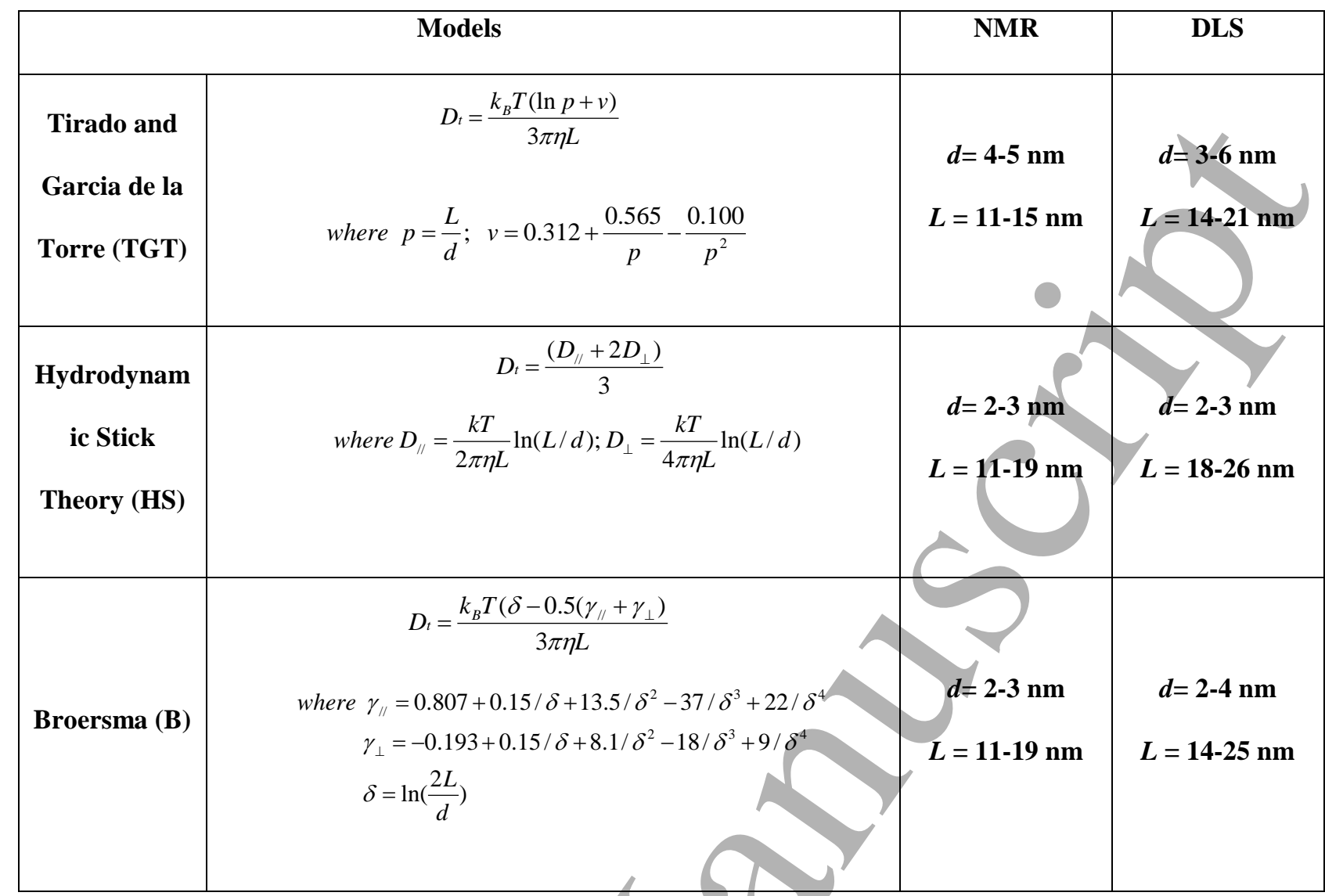

Table 1. Estimation of diameter (d) and lenght (L) by TGT, HS and B theories for $\mathrm{TiO}_{2} @ O$ OA rod-like nanoparticles for NMR and DLS measurements.

The dimensions estimated for nanorods according to the three models are not very different. However, taking into account the criticism to the HS theory that does not consider the "end effect” and to the $\mathbf{B}$ theory that is more reliable for very long rods (e.g filaments), we judged more sound the description made by the TGT model. Indeed, taking into account the OA layer around the nanorods, the TEM size estimation need to be increased of ca 1-2 nm depending on the conformation around the NP assumed by OA, and TGT theory resulted so the most appropriate.

3.2 $\mathrm{TiO}_{2}$ thin films preparation methods. $\mathrm{TiO}_{2}$ films were obtained by drop casting the sol suspensions of $\mathrm{TiO}_{2}$ nanorods and nanospheres obtained as described in the previous paragraph. The nanostructured glass supports remain transparent and suitable for an optical microscope observation. Drop casting covering method was adopted to uniformly cover the coverslips after many unsuccessful trials made with spin coating. The spin-coating covering method was also 
performed, but was indeed unable to give uniform and reproducible coatings, likely due to the too low viscosity of the suspension and the poor weak interactions between the silica $\mathrm{OH}$ on the surface and the apolar tails of OA on the nanoparticles. Attempts to make the NPs better interacting with the glass surface were made by pretreating the coverslips with a silane endowed with an apolar chain, but this strategy was not satisfactory using n-propyltrimethoxysilane for the pretreatment.

Glass coverslips obtained by drop casting were calcined (see Experimental) in order to assure the complete oxidation and removal of all the organic residues. The efficacy of calcination cycle was tested on samples of both nanorods and nanospheres $\mathrm{TiO}_{2}$ powders by analyzing the samples by FTIR spectroscopy. The comparison of the spectra recorded before and after calcination (Figure 4) well shows the completeness of the elimination of the organic surfactant and of the various solvents. Before the calcination process in both the spectra (a and c), several signals attributable to oleate capping ligand were present. The intense $\mathrm{C}-\mathrm{H}$ stretching due to the methylene groups of the olefin tail were visible (at 2920 and $2850 \mathrm{~cm}^{-1}$, asymmetric and symmetric, respectively), together with the shoulder at $2960 \mathrm{~cm}^{-1}$ due to the methyl terminal group and the weak peak at $3008 \mathrm{~cm}^{-1}$ due to the $\mathrm{C}-\mathrm{H}$ on the double bond [48-50].
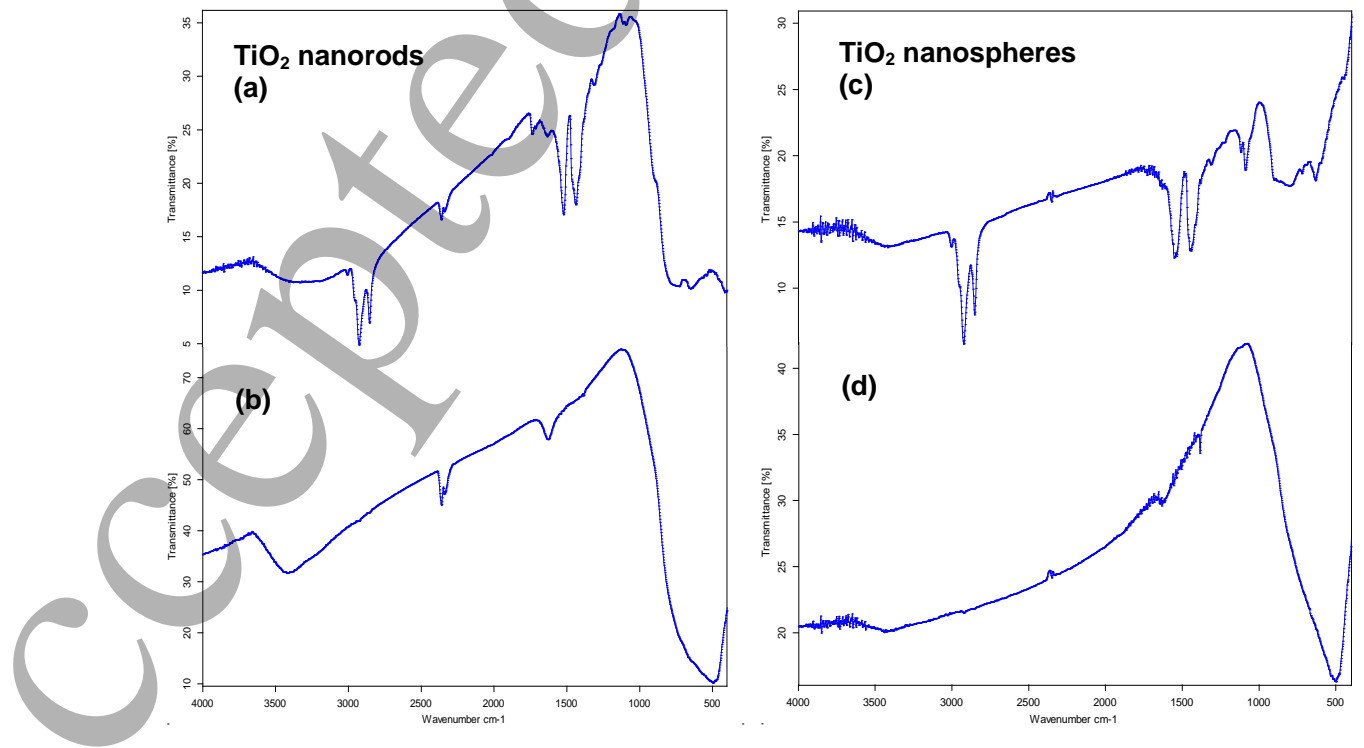

Figure 4. FT-IR spectra in $\mathrm{KBr}$ pellets of nanorods (sx) and nanospheres (dx) before (a, c) and after (b, d) calcination at $450^{\circ} \mathrm{C}$. 
The two intense and characteristic bands of the asymmetric and symmetric stretching centered at 1520 and $1436 \mathrm{~cm}^{-1}$ indicated that the binding to the surface of $\mathrm{TiO}_{2}$ was principally chelating bidentate (see scheme reported in Figure 1). In the case of $\mathrm{TiO}_{2}$ nanorods spectrum (a), a band at ca. $1720 \mathrm{~cm}^{-1}$ indicated the presence of oleic acid monomers, which was not detectable in the case of $\mathrm{TiO}_{2}$ nanospheres. Below $1000 \mathrm{~cm}^{-1}$ the Ti-O-Ti stretching bands were detectable as very broad bands. After the calcination process the region $400-1000 \mathrm{~cm}^{-1}$ gave a more defined peak, indicating a more ordered Ti-O-Ti framework. Moreover, after the calcination, only peaks due to coordinated surface water or superficial $\mathrm{OH}$ were detectable (at 3400 and $1640 \mathrm{~cm}^{-1}$ ), while all the organic component peaks disappear, confirming the efficacy of the thermal treatment.

3.3 $\mathrm{TiO}_{2}$ thin films characterization. The homogeneity as well as the wettability of the thin films prepared with sol gel suspensions of $\mathrm{TiO}_{2}$ nanorods and nanospheres have been investigated through water contact angle measurements. Measurements were repeated randomly depositing the water droplets in three different regions of the $\mathrm{TiO}_{2}$ films resulting in contact angle values ( $25^{\circ} \pm 1$ for nanospheres and $29^{\circ} \pm 1$ for nanorods) lower than for the reference glass substrate $\left(46^{\circ} \pm 1\right)$ (Figure 5$)$, in line with the fact that contac angle usually decreases by increasing the roughness of the support. This means a high wettability and hydrophilicity of the treated supports. 

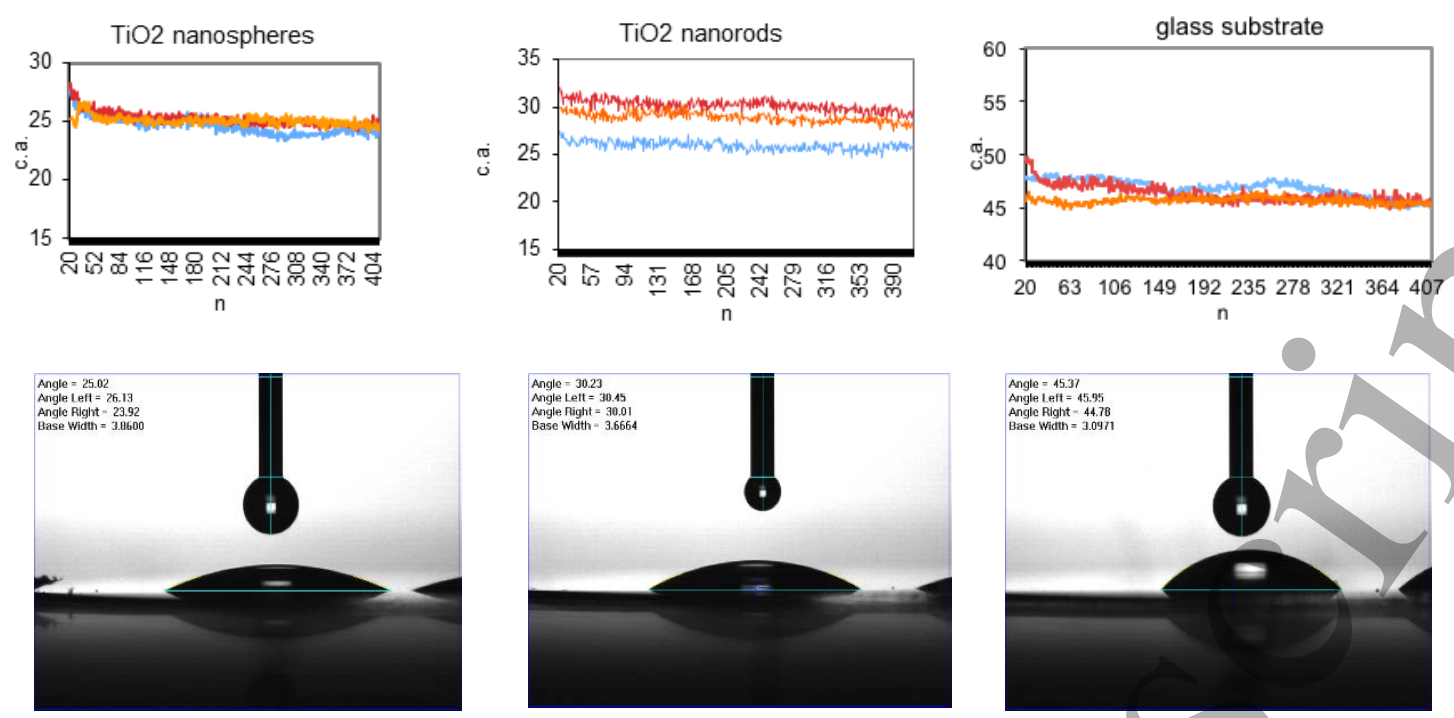

Figure 5. Water contact angle measurements on nanosphere and nanorod thin layers, and glass (from left to right respectively).

A SEM analysis was also performed on the nanorod sample. To this purpose, a silicon wafer was treated by drop casting with the same suspension used for the functionalization of glass substrates, revealing a dense covering of the nanorods (Figure 6 left). Moreover, the observation of the drop casted sample by zooming out the image (Figure 6 right) revealed the presence of a corrugated pattern formed during the withdrawal of the solvent.

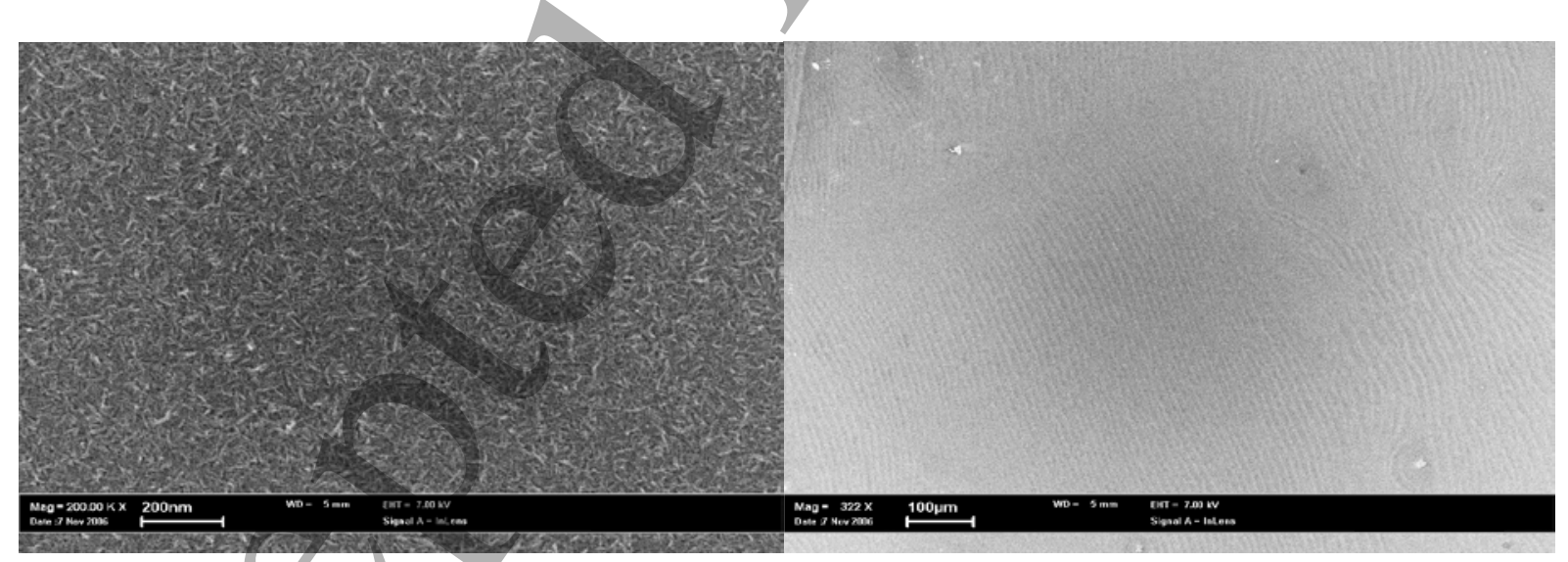

Figure 6. SEM images at two different magnifications of $\mathrm{TiO}_{2}$ nanorods deposited by drop-casting on a $\mathrm{Si}$ wafer.

3.4 MDCK cells adhesion study on different $\mathrm{TiO}_{2}$ based thin films. Study on the adhesion and proliferation of MDCK cells has been conducted comparing nanostructured titania thin films 
prepared by sol-gel method with plastic of multiwell plates (TCPS, tissue culture plastic substrate, positive control), coverslip glass (negative control) and cluster assembled titania films.

After 10000 cells per well were seeded, the cell shape and color were monitored over time as a function of several kinds of substrates. The shape of cells passed from spherical (when not still attached to the substrate) to elongated, with prolongations in evidence. At the same time the color varied from pearly and bright to grey.

Figure 7 reports digital photographs of the cells over time incubated on different substrates, qualitatively showing the cells response to the different substrates at the following time points 1 , 6 and $24 \mathrm{~h}$ by means the analysis of the cells morphology.

At $6 \mathrm{~h}$ the images showed that cell adhesion on the different $\mathrm{TiO}_{2}$ nanostructured substrates were lower than that observed on TCPS and greater than the glass substrate. The cell shapes show a polygonal-like morphology typical of the phenotype of adhered MDCK cells. At 24 h the cells incubated on TCPS, sol-gel nanorods $\mathrm{TiO}_{2}$ and ns- $\mathrm{TiO}_{\mathrm{x}}$ show either good proliferation and clustering, while on sol-gel nanospheres $\mathrm{TiO}_{2}$ the cells to have a significant slower proliferation. Moreover, the appearance of the cell clusters formed on the $\mathrm{TiO}_{2}$ substrates was very similar to that observed on TCPS, differently from what observed on the glass substrate, where are formed by a very low number of cells.

Some proliferation experiments were prolonged until $96 \mathrm{~h}$ (data not shown). In that case, we observed that while cells on TCPS had already reached the confluence and had started to die, on nanostructured $\mathrm{TiO}_{2}$ films the cells had just reached confluence, showing a delay of the cell growth on these nanostructured materials. The growth of MDCK cells on glass support was undoubtedly slower than that on $\mathrm{TiO}_{2}$ films. Optical images at $24 \mathrm{~h}$ indicate that the cells adhered on sol-gel nanorods are more elongated with respect to TCPS and the other nanostructured thin films. This behaviour could be ascribed to the occurrence of a guidance stimulus for the cell growth compliant with the asymmetric shape of the nanorods. This is a well- 
known effect for cells grown on aligned multiple nanogrooves or nanogratings [51,52], but not yet observed in randomly distributed elongated nanostructures.

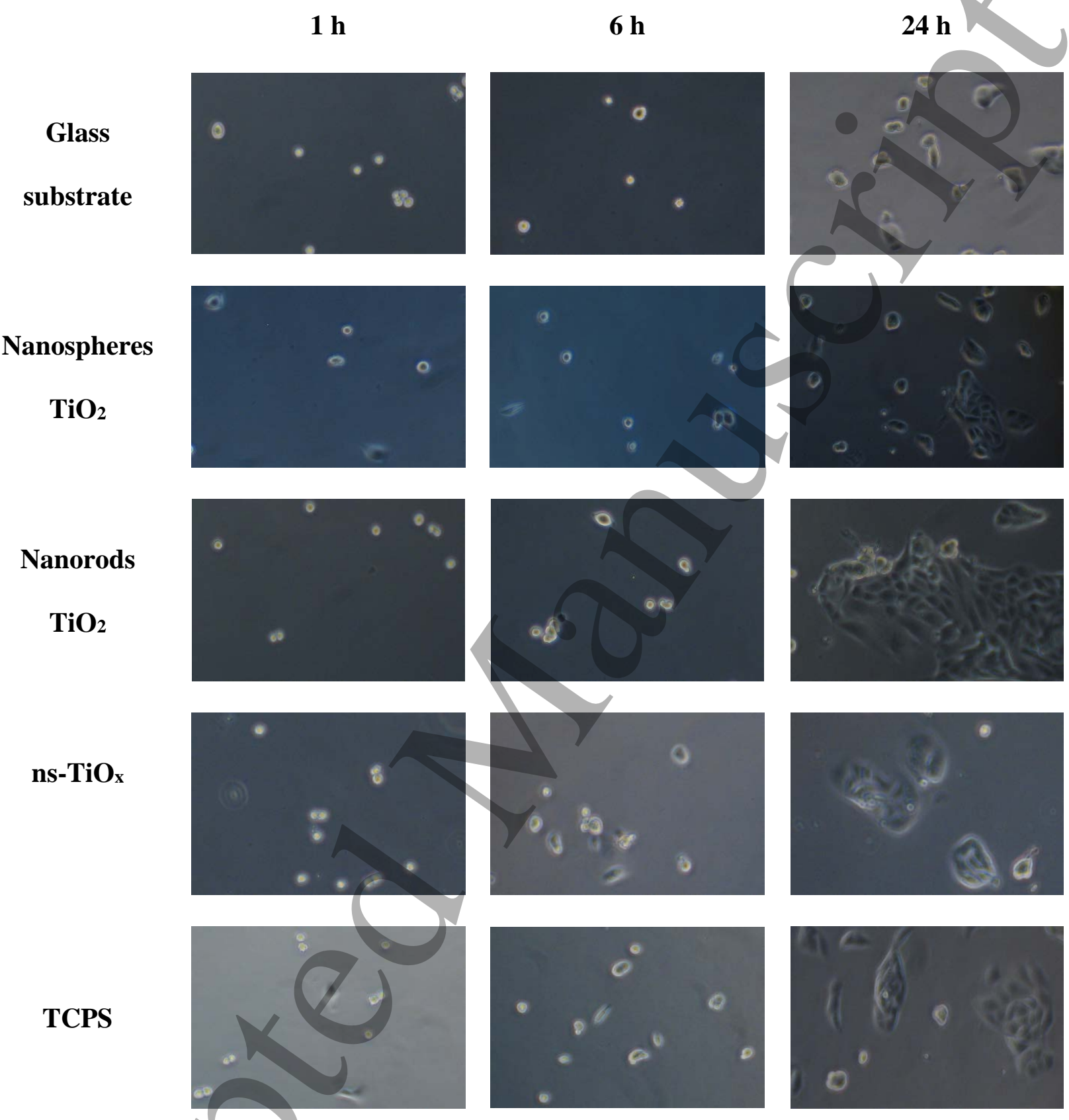

Figure 7. Digital photographs at different times of MDCK cells incubation on different substrates.

The quantitative evaluation of the adhesion of MDCK cells on the different kinds of substrates over time (1-4 h) was performed using the digital photographs of the cells. The images were analyzed counting all the elongated cells as attached cells and discarding all the spherical cells, considering them as not attached cells yet. Results have been reported in Figure 8. The 
nanostructured $\mathrm{TiO}_{2}$-based substrates show a good percentage of cellular adhesion, although retarded with respect to TCPS. Indeed, if we compare the number of adherent cells at fourth hour on the different substrate it can be concluded that the adhesion on plastic substrate was roughly double with respect to the $\mathrm{TiO}_{2}$-based substrates, which in turn revealed a cellular adhesion more than doubled with respect to the one observed on the glass coverslip.

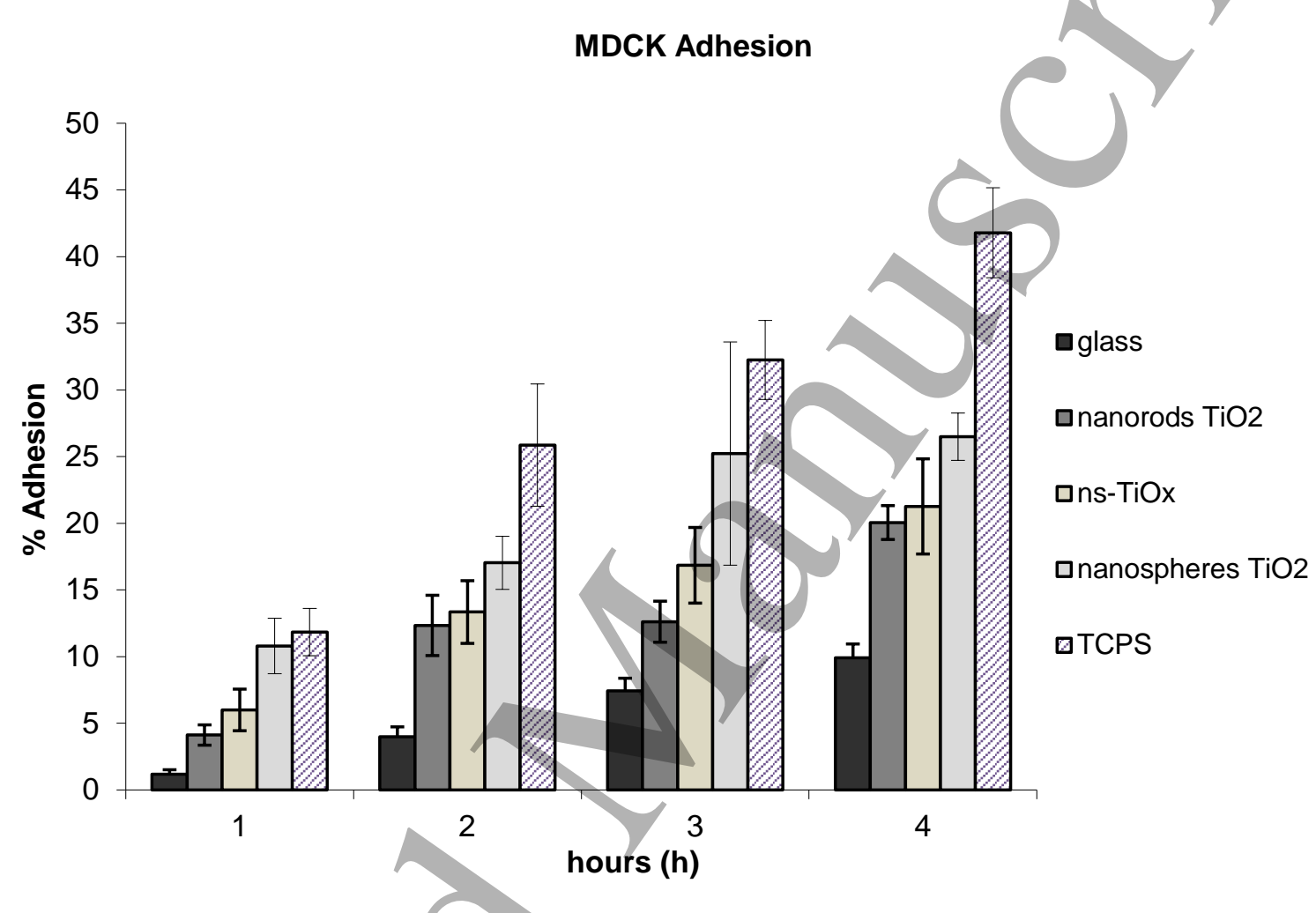

Figure 8. MDCK cell proliferation test results.

\section{Conclusions}

With this work we demonstrated that complementary analytical techniques (DLS, NMR, TEM, PXRD) can be combined for providing reliable information on the morphology and dimensions of two different set of apolar $\mathrm{TiO}_{2}$ nanoparticles, prepared by a sol gel method. Diffusion NMR experiments represent a good tool to estimate the dimensions of suspended (sol dispersions) spherical nano objects as well as rod shaped nanoparticles, provided the starting knowledge on the shape of the nano-object from other solid techniques analyses (as for example microscopy or PXRD analyses). The second goal of the work was the evaluation of the 
employment of this kind of material to produce thin nanostructured films, as new substrates for cell culture. The sol-gel $\mathrm{TiO}_{2}$ nanoparticles thin films were compared to a ns- $\mathrm{TiO}_{\mathrm{x}}$ thin film produced by PMCS technology. The results of proliferation and cell adhesion tests are very promising. In particular, the sol-gel nanorods $\mathrm{TiO}_{2}$ films promote a good cell adhesion and appear to affect the cell morphology of the MDCK, which usually prefer to maintain a polygonal-like shape with respect to elongated one for the formation of the epithelial tissue. Moreover, the adhesion and clustering amount is comparable to that of $\backslash$ ns- $\mathrm{TiO}_{\mathrm{x}}$, whose effectiveness as cell culture substrates has been widely assessed [26].

Quantitatively the cell adhesion is lower with respect to the TCPS but almost the double with respect the glass. However, the confluence for titania-based substrates is reached at about $96 \mathrm{~h}$.

Our results demonstrate that the use of sol-gel nanostructured $\mathrm{TiO}_{2}$ films allows a good control on the morphological and structural properties at the nanoscale of titania film and favor the cell adhesion and clustering organization. The production of nanostructured substrates via sol-gel has the advantages of being easily scalable and adopted for a wide range of support materials.

\section{References and Notes}

[1] Yao X, Song Y and Jiang L 2011 Applications of Bio-Inspired Special Wettable Surfaces Adv. Mater. 23 719-34

[2] Zhang C, Mcadams D A and Grunlan J C 2016 Nano/Micro-Manufacturing of Bioinspired Materials: a Review of Methods to Mimic Natural Structures Adv. Mater. 28 6292-321

[3] Schulte C, Podestà A, Lenardi C, Tedeschi G and Milani P 2017 Quantitative Control of Protein and Cell Interaction with Nanostructured Surfaces by Cluster Assembling Acc. Chem. Res. 50 231-9

[4] Clause K C and Barker T H 2013 Extracellular matrix signaling in morphogenesis and repair Curr. Opin. Biotechnol. 24 830-3

[5] Abagnale G, Steger M, Nguyen V H, Hersch N, Sechi A, Joussen S, Denecke B, Merkel R, Hoffmann B, Dreser A, Schnakenberg U, Gillner A and Wagner W 2015 Surface topography enhances differentiation of mesenchymal stem cells towards osteogenic and adipogenic lineages Biomaterials 61 316-26 
[6] Buttery R C, Rintoul R C and Sethi T 2004 Small cell lung cancer: the importance of the extracellular matrix Int. J. Biochem. Cell Biol. 36 1154-60

[7] He X, Lee B and Jiang Y 2016 Cell-ECM Interactions in Tumor Invasion Adv. Exp. Med. Biol. 936 73-91

[8] Dalby M J, Gadegaard N and Oreffo R O C 2014 Harnessing nanotopography and integrin-matrix interactions to influence stem cell fate Nat. Mater. 13 558-69,

[9] Schulte C, Rodighiero S, Cappelluti M A, Puricelli L, Maffioli E, Borghi F, Negri A, Sogne E, Galluzzi M, Piazzoni C, Tamplenizza M, Podesta A, Tedeschi G, Lenardi C and Milani P 2016 Conversion of nanoscale topographical information of cluster-assembled zirconia surfaces into mechanotransductive events promotes neuronal differentiation $J$. Nanobiotechnology 14 1-24

[10] Lord M S, Foss M and Besenbacher F 2010 Influence of nanoscale surface topography on protein adsorption and cellular response Nano Today 5 66-78

[11] Roach P, Farrar D and Perry C C 2005 Interpretation of Protein Adsorption: SurfaceInduced Conformational Changes J. Am. Chem. Soc. 127 8168-73

[12] Shin H, Jo S and Mikos A G 2003 Biomimetic materials for tissue engineering Biomaterials 24 4353-64

[13] Kim T G, Shin H and Lim D W 2012 Biomimetic Scaffolds for Tissue Engineering Adv. Funct. Mater. 22 2446-68

[14] Schneider J, Matsuoka M, Takeuchi M, Zhang J, Horiuchi Y, Anpo M and Bahnemann D W 2014 Understanding $\mathrm{TiO}_{2}$ Photocatalysis: Mechanisms and Materials Chem. Rev. 114 9919-86

[15] Macwan D P, Dave P N and Chaturvedi S 2011 A review on nano- $\mathrm{TiO}_{2}$ sol-gel type syntheses and its applications J. Mater. Sci. 46 3669-86

[16] Li Q, Mahendra S, Lyon D Y, Brunet L, Liga M V, Li D and Alvarez P J J 2008 Antimicrobial nanomaterials for water disinfection and microbial control: Potential applications and implications Water Res. 42 4591-602

[17] Tachikawa $\mathrm{T}$, Fujitsuka $\mathrm{M}$ and Majima $\mathrm{T} 2007$ Mechanistic Insight into the $\mathrm{TiO}_{2}$ Photocatalytic Reactions: Design of New Photocatalysts J. Phys. Chem. C 111 5259-75

[18] Hamann T W, Jensen R A, Martinson A B F, Van Ryswyk H and Hupp J T 2008 Advancing beyond current generation dye-sensitized solar cells Energy Environ. Sci. 166

[19] Ondersma J W and Hamann T W 2013 Recombination and redox couples in dye-sensitized solar cells Coord. Chem. Rev. 257 1533-43

[20] Brunette D M, Tengvall P, Textor M and Thomsen P 2001 Titanium in Medicine Material Science, Surface Science, Engineering, Biological Responses and Medical Applications (Berlin, Heidelberg: Springer Berlin Heidelberg)

[21] Ohlstein B, Kai T, Decotto E and Spradling A 2004 The stem cell niche: theme and variations Curr. Opin. Cell Biol. 16 693-9 
[22] Zipori D 2004 Opinion: The nature of stem cells: state rather than entity Nat. Rev. Genet. 5 873-8

[23] Park J, Bauer S, Schmuki P and von der Mark K 2009 Narrow Window in Nanoscale Dependent Activation of Endothelial Cell Growth and Differentiation on $\mathrm{TiO}_{2} \mathrm{Nanotube}$ Surfaces Nano Lett. 9 3157-64

[24] Lee C J, Blumenkranz M S, Fishman H A and Bent S F 2004 Controlling Cell Adhesion on Human Tissue by Soft Lithography Langmuir 20 4155-61

[25] Zhang S 2003 Fabrication of novel biomaterials through molecular self-assembly Nat. Biotechnol. 21 1171-8

[26] Carbone R, Marangi I, Zanardi A, Giorgetti L, Chierici E, Berlanda G, Podesta A, Fiorentini F, Bongiorno G and Piseri P 2006 Biocompatibility of cluster-assembled nanostructured $\mathrm{TiO}_{2}$ with primary and cancer cells Biomaterials 27 3221-9

[27] Advincula M C, Rahemtulla F G, Advincula R C, Ada E T, Lemons J E and Bellis S L 2006 Osteoblast adhesion and matrix mineralization on sol-gel-derived titanium oxide Biomaterials 27 2201-12

[28] Cozzoli P D, Kornowski A and Weller H 2003 Low-Temperature Synthesis of Soluble and Processable Organic-Capped Anatase $\mathrm{TiO}_{2}$ Nanorods J. Am. Chem. Soc. 125 14539-48

[29] Carbone R, Marangi I, Zanardi A, Giorgetti L, Chierici E, Berlanda G, Podesta A, Fiorentini F, Bongiorno G and Piseri P 2006 Biocompatibility of cluster-assembled nanostructured $\mathrm{TiO}_{2}$ with primary and cancer cells Biomaterials 27 3221-9

[30] De Astis S, Corradini I, Morini R, Rodighiero S, Tomasoni R, Lenardi C, Verderio C, Milani P and Matteoli M 2013 Nanostructured $\mathrm{TiO}_{2}$ surfaces promote polarized activation of microglia, but not astrocytes, toward a proinflammatory profile Nanoscale 5 10963-74

[31] Wegner K, Piseri P, Tafreshi H V and Milani P 2006 Cluster beam deposition: a tool for nanoscale science and technology J. Phys. Appl. Phys. 39 R439-59

[32] Caruso T, Lenardi C, Agostino R G, Amati M, Bongiorno G, Mazza T, Policicchio A, Formoso V, Maccallini E, Colavita E, Chiarello G, Finetti P, Sutara F, Skala T, Piseri P, Prince K C and Milani P 2008 Electronic structure of cluster assembled nanostructured $\mathrm{TiO}_{2}$ by resonant photoemission at the Ti $L_{2,3}$ edge J. Chem. Phys. 128094704

[33] Wu D H, Chen A and Johnson C S 1995 Flow Imaging by Means of 1D Pulsed-FieldGradient NMR with Application to Electroosmotic Flow J. Magn. Reson. A 115 123-6

[34] TOPAS Version 3.0, Bruker AXS, Karlsruhe, Germany 2005

[35] DIFFRAC.EVA is a part of the DIFFRAC.SUITE ${ }^{\mathrm{TM}}$ Bruker programs.

[36] Erbil H Y 2012 Evaporation of pure liquid sessile and spherical suspended drops: A review Adv. Colloid Interface Sci. 170 67-86

[37] Stilbs P 1987 Fourier transform pulsed-gradient spin-echo studies of molecular diffusion Próg. Nucl. Magn. Reson. Spectrosc. 19 1-45 
[38] Walderhaug H, Hansen F K, Abrahmsen S, Persson K and Stilbs P 1993 Associative thickeners: NMR self-diffusion and rheology studies of aqueous solutions of hydrophobically modified poly (oxyethylene) polymers J. Phys. Chem. 97 8336-42

[39] Donghi D, Maggioni D, D’Alfonso G, Amigoni F, Ranucci E, Ferruti P, Manfredi A, Fenili F, Bisazza A and Cavalli R 2009 Tricarbonyl-Rhenium Complexes of a ThiolFunctionalized Amphoteric Poly(amidoamine) Biomacromolecules 10 3273-82

[40] Cabrita E J, Berger S, Bräuer P and Kärger J 2002 High-Resolution DOSY NMR with Spins in Different Chemical Surroundings: Influence of Particle Exchange J. Magn. Reson. 157 124-31

[41] Freddi S, D’Alfonso L, Collini M, Caccia M, Sironi L, Tallarida G, Caprioli S and Chirico G 2009 Excited-State Lifetime Assay for Protein Detection on Gold Colloids-Fluorophore Complexes J. Phys. Chem. C 113 2722-30

[42] In the case of spheres the diffraction pattern correspondent to the anantase spherical nanoparticles has been obtained only after a calcination process performed on the precipitated powder, heating for $1 \mathrm{~h}$ at $400{ }^{\circ} \mathrm{C}$

[43] Tirado M M and de la Torre J G 1979 Translational friction coefficients of rigid, symmetric top macromolecules. Application to circular cylinders J. Chem. Phys. 71 2581-7

[44] Wong A, Ida R, Spindler L and Wu G 2005 Disodium Guanosine 5‘-Monophosphate SelfAssociates into Nanoscale Cylinders at $\mathrm{pH}$ 8: A Combined Diffusion NMR Spectroscopy and Dynamic Light Scattering Study J. Am. Chem. Soc. 127 6990-8

[45] Vasanthi R, Bhattacharyya S and Bagchi B 2002 Anisotropic diffusion of spheroids in liquids: Slow orientational relaxation of the oblates J. Chem. Phys. 116 1092-6

[46] Broersma S 1981 Viscous force and torque constants for a cylinder J. Chem. Phys. 74 6989-90

[47] Perrin F 1936 Mouvement Brownien d'un ellipsoide (II). Rotation libre et dépolarisation des fluorescences. Translation et diffusion de molécules ellipsoidales J. Phys. Radium 7 111

[48] Thistlethwaite P J and Hook M S 2000 Diffuse Reflectance Fourier Transform Infrared Study of the Adsorption of Oleate/Oleic Acid onto Titania Langmuir 16 4993-8

[49] Nara M, Torii H and Tasumi M 1996 Correlation between the Vibrational Frequencies of the Carboxylate Group and the Types of Its Coordination to a Metal Ion: An ab Initio Molecular Orbital Study J. Phys. Chem. 100 19812-7

[50] Thistlethwaite P J, Gee M L and Wilson D 1996 Diffuse Reflectance Infrared Fourier Transform Spectroscopic Studies of the Adsorption of Oleate/Oleic Acid onto Zirconia Langmuir 12 6487-91

[51] Ferrari A, Cecchini M, Serresi M, Faraci P, Pisignano D and Beltram F 2010 Neuronal polarity selection by topography-induced focal adhesion control Biomaterials 31 4682-94

[52] Kim D-H, Provenzano P P, Smith C L and Levchenko A 2012 Matrix nanotopography as a regulator of cell function J. Cell Biol. 197 351-60 